\title{
Initial Experience of Endoscopic Thyroidectomy Using Bilateral Axillary Breast and Transoral Vestibular Approach in Georgia
}

Jae Cheol Jung, M.D. ${ }^{1}$, Giorgi Chantladze, M.D. ${ }^{2}$, Vladimer Kharebadze, M.D. ${ }^{2}$, Jong-Hyuk Ahn, M.D. ${ }^{1}$, Jae Hwan Kim, M.D. ${ }^{1}$, Jin Wook Yi, M.D., M.S. ${ }^{1}$, Edisher Sikharulidze, M.D., Ph.D. ${ }^{2}$

${ }^{1}$ Department of Surgery, Inha University Hospital, Inha University College of Medicine, Incheon, Korea, ${ }^{2}$ Department of Surgery, Aversi Clinic, Thilisi, Georgia

Purpose: Remote access thyroid surgery using a bilateral axillary breast approach (BABA) or a transoral endoscopic thyroidectomy vestibular approach (TOETVA) are increasingly performed worldwide. In the Caucasus, these methods were first applied in the Republic of Georgia. This study compares these two methods of endoscopic thyroid surgery performed on patients in a tertiary hospital in Tbilisi, Georgia.

Methods: Between December 2015 and January 2018, 41 patients underwent endoscopic thyroid surgery at the Aversi Clinic, including 32 who underwent BABA endoscopic thyroidectomy for benign nodules and nine who underwent TOETVA for thyroid cancers. Patients' medical records were retrospectively reviewed.

Results: Tumors were significantly larger $(2.38 \pm 0.38 \mathrm{~cm}$ versus $1.70 \pm 0.31 \mathrm{~cm}, p$ value $<0.001)$, operation time was significantly longer (177.66 $\pm 21.02 \mathrm{~min}$ versus $116.66 \pm 5.59 \mathrm{~min}, p$ value $<0.001$ ), and blood loss was significantly greater $(149.07 \pm 28.10 \mathrm{ml}$ versus $102.22 \pm 8.33 \mathrm{ml}, p$ value $<0.001)$ in patients who underwent BABA than TOETVA. There were no significant differences in postoperative complications between the two groups.

Conclusion: Remote access thyroid surgery, either BABA or TOETVA, was successfully started, without harmful complications, at the Aversi Clinic in Tbilisi, Georgia. BABA is suitable for large sized benign nodules and TOETVA for thyroid cancers with central lymph node dissection.

Keywords: Thyroid nodule, Thyroid neoplasms, Minimally invasive surgical procedures, Natural orifice endoscopic surgery, Thyroidectomy
Received May 18, 2020

Revised 1st June 25, 2020

2nd July 20, 2020

3rd August 14, 2020

Accepted August 20, 2020

Corresponding author

Jin Wook Yi

Department of Surgery, Inha

University Hospital, Inha University

College of Medicine, 27 Inhang-ro,

Jung-gu, Incheon 22332, Korea

Tel: +82-32-890-2738

Fax: +82-32-890-3549

E-mail: jinwook.yi@inha.ac.kr

ORCID:

https://orcid.org/0000-0002-9296-8443

Edisher Sikharulidze

Department of Surgery, Aversi Clinic, 27b Vazha Pshavela Ave, Tbilisi 0160, Georgia

Tel: +995-32-2500-700

Fax: +995-32-239-9370

E-mail: edisikharulidze@gmail.com ORCID:

https://orcid.org/0000-0001-9243-3927

Copyright $\odot 2020$ The Journal of Minimally Invasive Surgery. All rights reserved.

\section{INTRODUCTION}

Thyroid cancer has one of the highest incidences of solid organ malignancies, and the highest incidence of malignancies of the endocrine system. ${ }^{1}$ Worldwide, about 567,000 patients are diagnosed with thyroid cancer annually, with thyroid cancer ranked the ninth most common cancer and the fifth most prevalent cancer among women. ${ }^{2}$ Since the early 1980s, the incidence of thyroid cancer, especially papillary thyroid carcinoma, has gradually increased in many countries. ${ }^{3,4}$ In Eastern Europe, 
the incidence rate of thyroid cancer in 2018 was 9.7 per 100,000 in women and 2.4 per 100,000 in men. ${ }^{2}$

The recommended treatment for thyroid cancer is surgical removal of the thyroid gland. The standard method of open thyroidectomy with anterior neck incision is called the "Kocher method". However, the open thyroid surgery method has the disadvantage of leaving a permanent scar on the anterior neck, which can have an unfavorable effect on patient quality of life. Women most frequently diagnosed with thyroid cancer are aged in their 30s and 40s, making cosmetic outcomes very important to their daily lives. ${ }^{5}$ These cosmetic concerns have led to the development of new surgical methods that do not leave visible surgical scars on the neck. ${ }^{7}$

One of the most utilized methods of remote access thyroid surgery is the bilateral axillary breast approach (BABA). ${ }^{8}$ Thyroidectomy via the bilateral axillary breast approach (BABA) employs an endoscopic instrument to place trocars in both the breast and axillary region. This method has shown favorable cosmetic outcomes, as well as surgical and oncologic safety. ${ }^{9}$ However, the BABA method still leaves scars on the breasts and axillary areas, and requires a wide area for subcutaneous flap dissection. A new natural orifice thyroid surgery technique, called the transoral endoscopic thyroidectomy vestibular approach (TOETVA), was introduced in 2016, mostly to treat benign thyroid nodules. ${ }^{10-12}$ The transoral endoscopic thyroidectomy vestibular approach (TOETVA) is a surgical procedure that involves inserting a trocar into the mouth for thyroidectomy. Subsequently, TOETVA has been used to treat thyroid cancer. ${ }^{10,13-15}$ This method has shown surgical and oncologic safety, as well as favorable cosmetic outcomes, with a reduced area of subcutaneous flap dissection compared with the BABA method. ${ }^{10}$

The Republic of Georgia is located in the Caucasus region of Eastern Europe. The Aversi Clinic in Tbilisi, the capital of Georgia, started performing endoscopic BABA in 2015 and TOETVA in 2018, making it the first center in the Caucasus to perform these operations. The present study compares the outcomes in patients who underwent endoscopic thyroid surgery using these two methods.

\section{MATERIALS AND METHODS}

Between December 2015 and January 2018, 41 patients underwent endoscopic thyroid surgery at the Georgia Aversi Clinic. Of these 41 patients, 32 underwent BABA endoscopic surgery and nine underwent TOETVA. For benign thyroid nodules that do not need central node dissection, the BABA approach is recommended, and for thyroid cancers that need central node dissection, the TOETVA approach is recommended.

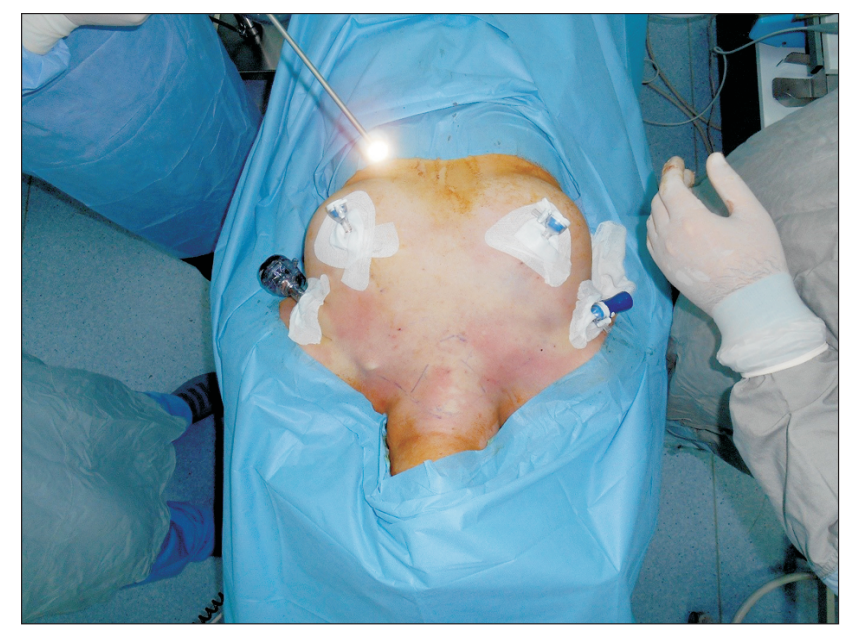

Fig. 1. Trocar insertion of BABA for endoscopic thyroidectomy.

\section{Description of the BABA technique}

The patient was placed in a supine position with neck extension, under general anesthesia and orotracheal intubation. The intended flap area was drawn with a surgical marker and a 1:200,000 solution of epinephrine in saline was injected subcutaneously into this area. Bilateral circumareolar and axillary incisions were created and blunt dissection was performed with a vascular tunneller. Trocars were inserted into both the breast and axillary region (Fig. 1). The subcutaneous flap was completed using the energy device while maintaining $\mathrm{CO}_{2}$ at 5 to $7 \mathrm{mmHg}$ Monopolar electrocautery was used for midline division and lateral dissection. The isthmus was divided by the energy device (Fig. 2A). After isolation of the thyroid gland and strap muscle, the latter was laterally retracted with a snake retractor (Fig. 2B). The recurrent laryngeal nerve (RLN) and inferior parathyroid gland were identified by careful dissection of the inferolateral side of the thyroid gland (Fig. 2C). The thyroid gland was separated from the trachea while dissecting upward, allowing the dissection of Berry's ligament. The upper thyroid pole was dissected with the energy device (Fig. 2D), and the specimen was removed using an endo-plastic bag. The midline of the strap muscle and the skin incisions were closed with absorbable sutures.

\section{Description of the TOETVA technique}

The patient was placed in a supine position with neck extension, under general anesthesia and orotracheal intubation, and the head was firmly fixed to prevent its rotation during surgery. The surgeon was positioned at the patient's headside. The oral cavity was disinfected using $0.05 \%$ chlorhexidine solution. The borders of the flap were set by delineating the thyroid cartilage as the upper border, the suprasternal notch as the lower border, 

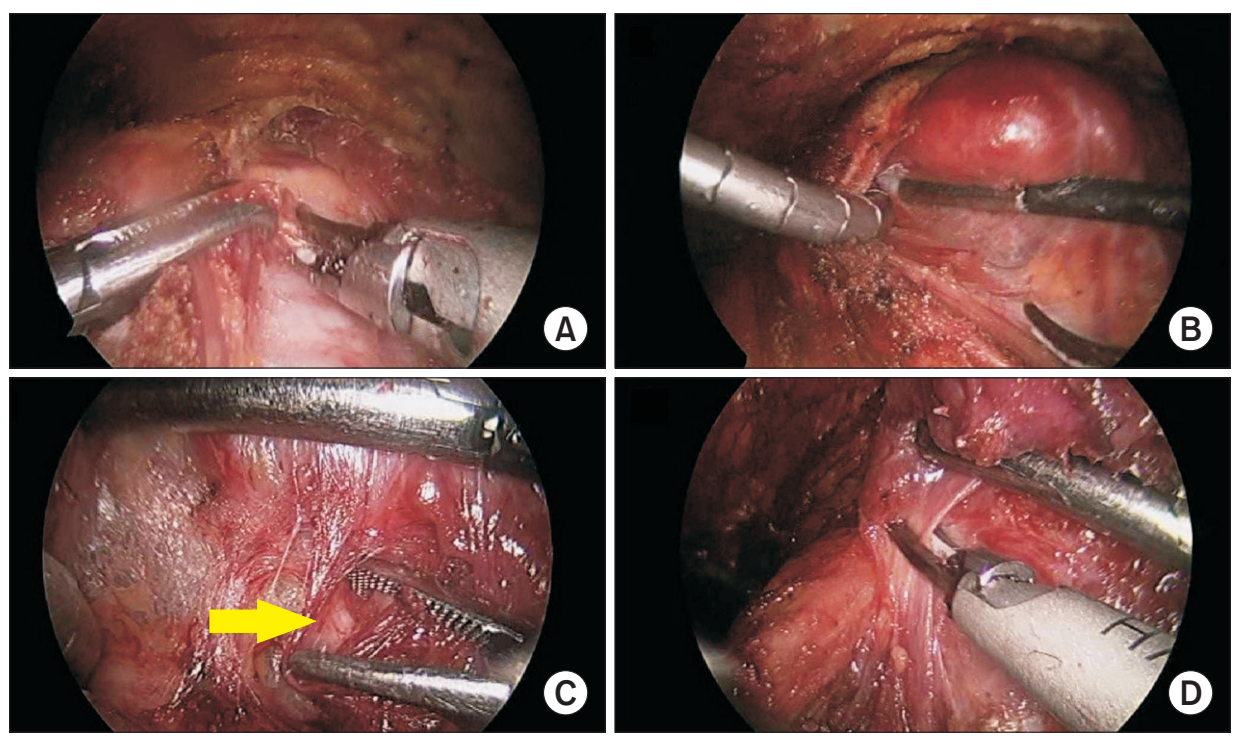

Fig. 2. Endoscopic view of BABA right Iobectomy. (A) Isthmus division, (B) Thyroid mobilization with strap muscle retraction, (C) Recurrent laryngeal nerve identification (yellow arrow points to the recurrent laryngeal nerve), (D) Superior pole ligation.

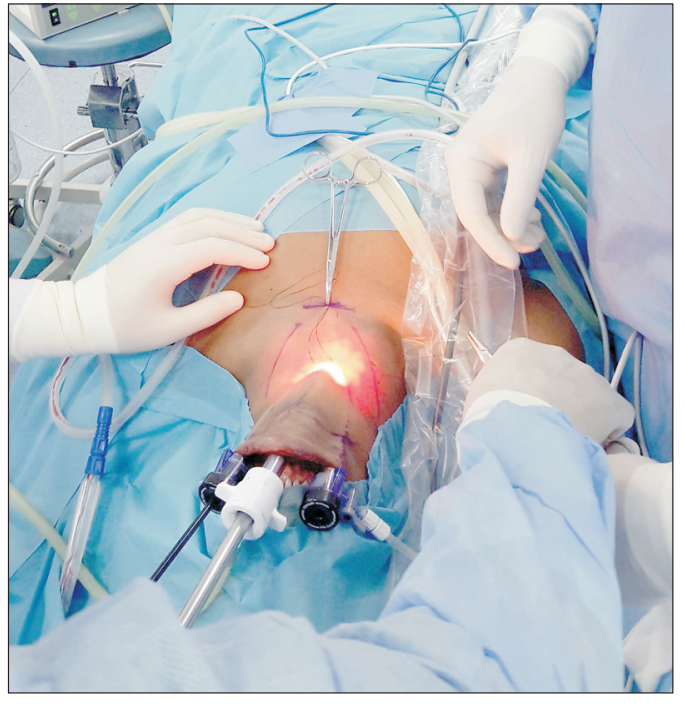

Fig. 3. Trocar insertion of TOETVA

and the anterior borders of both sternocleidomastoid muscles as the lateral borders. Three trocar insertion sites were used (Fig. 3). An $11 \mathrm{~mm}$ incision for the camera port was created between the lower lip and the frenulum. Using a Verress needle, a 1:200,000 solution of epinephrine in saline was injected subcutaneously between the mentalis muscle and the periosteum of the mandible tip, followed by blunt dissection of the subplatysmal flap with a small tunneller. A trocar $11 \mathrm{~mm}$ in diameter was inserted through the sub-mentalis area and a $10 \mathrm{~mm} 30^{\circ}$ laparoscope was inserted to check the proper layer of the initial flap. The area was insufflated with $\mathrm{CO}_{2}$ gas at $6 \mathrm{mmHg}$ pressure and at a flow rate of $15 \mathrm{~L} /$ hour. Two $5 \mathrm{~mm}$ trocars for endoscopic instruments were inserted, far lateral from both incisions and close to the border of the lip to prevent mental nerve injury, as previously described. ${ }^{13}$ The strap muscles were divided by endoscopic electrocautery, and the isthmus was dissected with an energy device (Fig. 4A). The thyroid gland was rotated in the opposite direction, and soft tissue between the thyroid and strap muscle was dissected. To enlarge the space between the thyroid and the strap muscle, 3-0 silk sutures were applied from outside of the skin (Fig. 4B). After dissection and ligation of the middle thyroid vein, the superior pole of the thyroid gland was identified by clearing the cricothyroid space. The superior thyroid vessels were ligated with the energy device with pull-out of the superior pole from its bed (Fig. 4C). The thyroid gland was fully rotated medially, and the RLN was identified in the tracheo-esophageal groove (Fig. 4D). The superior parathyroid could generally be saved during upper pole dissection, and the inferior parathyroid could be preserved during clearing of the tissue around the RLN. The rest of the tissue around Berry's ligament was subsequently removed, completing thyroid lobectomy. In patients with papillary thyroid carcinoma, central node dissection can be easily performed during the lobectomy due to the cranio-caudal endoscopic view. Either prophylactic or therapeutic central node dissection was used for all papillary thyroid carcinoma patients undergoing TOETVA. The specimen was removed through the $11 \mathrm{~mm}$ incision site using an endo-plastic bag. The oral vestibule surgical wound was closed using absorbable sutures.

\section{Intraoperative neuro-monitoring}

For endoscopic thyroid surgery, neuromonitoring with NIM-3 equipment was used (Medtronic Xomed, Jacksonville, FL, USA) In patients undergoing $\mathrm{BABA}$, the probe cable was connected to the endoscopic electrocautery. In patients undergoing TOETVA, 

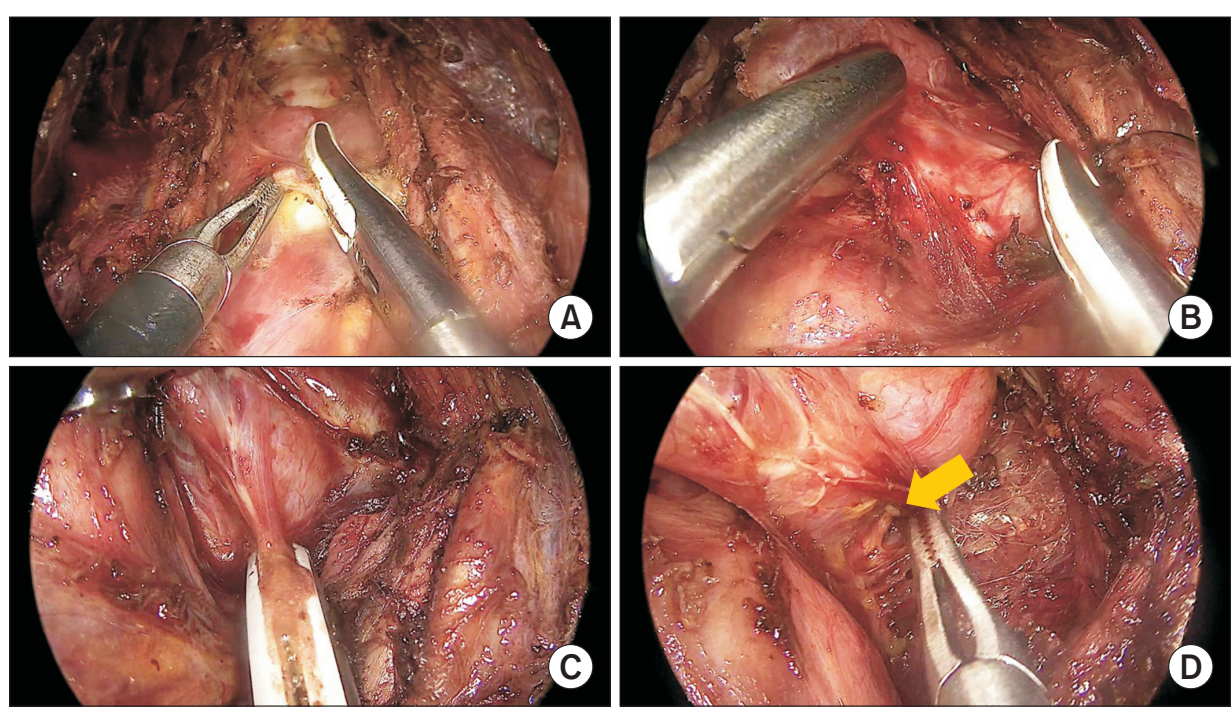

Fig. 4. Endoscopic view of right lobectomy by TOETVA. (A) Isthmus division, (B) Thyroid mobilization with hanging suture of the strap muscle, (C) Superior pole ligation, (D) Recurrent laryngeal nerve identification (yellow arrow points to the recurrent laryngeal nerve).

a long probe was connected to the Medtronic device. All 38 patients underwent surgery using intraoperative neuromonitoring.

\section{Hospital management and defining complications}

All patients were hospitalized the day before surgery and were allowed to be discharged 2 or 3 days after surgery. The discharge criteria for patients were improved general condition, stable vital signs, and drain removal. Visual Analog Scale (VAS) scores were recorded daily by nurses, beginning on the first morning. The visual analog scale (VAS) is a validated, subjective measure of acute and chronic pain. RLN function was evaluated by video-assisted laryngoscopic evaluation, with RLN injury defined as impairment of cord motility. RLN injury was defined as permanent if impairment of vocal cord motility persisted more than 6 months after surgery; otherwise, it was considered transient. Hypocalcemia was defined as clinical symptoms. Blood calcium levels after surgery were generally not checked at our institution.

\section{Data and statistics}

Patients' medical records were retrospectively reviewed. Factors that were evaluated included age, gender, tumor size, tumor location, fine needle aspiration cytology, pathologic diagnosis, surgical extent, operation time, blood loss, visual pain score, hospital stay after surgery, information about radioactive iodine therapy, and complications. The amount of blood loss was estimated by measuring the amount of blood in the vacuum suction device and cotton swabs. The operation time was defined as the time from skin incision to closing the wound. Numerical variables were compared by unpaired t-tests. Because this study included a small number of patients, Fischer's exact tests were used for cross tabulation analysis. All statistical analyses were performed using R software version 3.3.2 (www.R-project.org), with statistical significance defined as a $p$ value $<0.05$. The study protocol was reviewed and approved by the institutional review board of Inha University Hospital.

\section{RESULTS}

During the study period, 41 patients, all women, underwent thyroid surgery, including 32 who underwent BABA endoscopic surgery and nine who underwent TOETVA. The mean ages of the two groups did not differ significantly. Of the 32 patients who underwent BABA, four had unilateral and 28 had bilateral thyroid lesions, whereas all nine patients who underwent TOETVA had unilateral thyroid lesions. All patients in the BABA group were preoperatively diagnosed with benign lesions, whereas all patients in the TOETVA group were diagnosed with malignancy or were suspicious for malignancy. At final pathologic diagnosis, all patients in the BABA group had follicular adenoma or multinodular goiter, whereas eight patients in the TOETVA group had papillary thyroid carcinoma (Table 1).

Table 2 describes the surgical variables and outcomes of each method. In the BABA group, three patients underwent lobectomy, and 29 underwent total thyroidectomy. In the TOETVA group, all nine patients underwent total thyroidectomy with central lymph node dissection. Tumors were larger in size in the BABA than in the TOETVA group $(2.38 \pm 0.38 \mathrm{~cm}$ versus $1.70 \pm 0.31 \mathrm{~cm}, p$ value $<0.001)$. Operation time was significantly longer (177.66 $\pm 21.02 \mathrm{~min}$ versus $116.66 \pm 5.59 \mathrm{~min}, p$ value $<0.001$ ), and blood loss was significantly greater $(149.07 \pm 28.10 \mathrm{ml}$ versus $102.22 \pm 8.33 \mathrm{ml}, p$ value $<0.001)$ in the BABA than in the TOETVA group. There were no differences in VAS scores between the two groups on postoperative days $1(3.59 \pm 0.5$ versus $3.44 \pm 0.53)$ and $2(2.59 \pm 0.50$ versus $2.44 \pm 0.53)$. Mean postoperative hospital 
Table 1. Clinical characteristics of patients who underwent endoscopic thyroidectomy by the BABA and TOETVA methods

\begin{tabular}{|c|c|c|c|}
\hline Variables & $\mathrm{BABA}(\mathrm{N}=32)$ & TOETVA $(\mathrm{N}=9)$ & $p$ value \\
\hline Age (Years, mean \pm sd) & $35.09 \pm 11.20$ & $31.89 \pm 9.17$ & 0.392 \\
\hline \multicolumn{4}{|l|}{ Gender } \\
\hline Female & 32 & 9 & NA \\
\hline Tumor location & & & $<0.001$ \\
\hline Bilateral & 28 & 0 & \\
\hline Left & 1 & 5 & \\
\hline Right & 3 & 4 & \\
\hline Fine needle aspiration cytology & & & $<0.001$ \\
\hline Benign & 32 & 0 & \\
\hline Suspicious for malignancy & 0 & 1 & \\
\hline Malignancy & 0 & 8 & \\
\hline Pathologic diagnosis & & & $<0.001$ \\
\hline Follicular adenoma & 4 & 1 & \\
\hline Multinodular goiter & 28 & 0 & \\
\hline Papillary thyroid carcinoma & 0 & 8 & \\
\hline
\end{tabular}

stay was 3 days in the BABA group and 2 days in the TOETVA group. There were no significant between-group differences in postoperative complications (Table 2). Only five BABA patients and one TOETVA patent showed temporary hypocalcemia symptoms, which returned to normal within 10 days. There was no mental nerve palsy or surgical site infection in the TOETVA group.

Table 3 shows the oncologic outcomes in the eight patients

Table 3. Oncologic outcomes in patients with papillary thyroid carcinoma who underwent TOETVA

\begin{tabular}{lc}
\hline \multicolumn{1}{c}{ Variables } & Value \\
\hline $\begin{array}{l}\text { Number of retrieved lymph nodes } \\
\text { (mean } \pm \text { sd, numbers) }\end{array}$ & $4.78 \pm 2.82(0 \sim 10)$ \\
Number of metastatic lymph nodes & $1.33 \pm 0.87(0 \sim 3)$ \\
(mean \pm sd, numbers) & \\
Radioactive iodine therapy & $120 \pm 0$ \\
1st RAl dose (mean $\pm S D, m C i)$ & \\
TSH level before RAl (mean $\pm S D, \mu l \mathrm{U} / \mathrm{ml})$ & $73.22 \pm 8.56(60 \sim 82.5)$ \\
Stimulated Tg level before RAl & $0.87 \pm 0.07(0.76 \sim 0.95)$ \\
(mean $\pm S D, n g / m l)$ & \\
\hline
\end{tabular}

$\mathrm{RAl}=$ radioactive iodine therapy.

Table 2. Comparison of surgical variables and outcomes in patients who underwent BABA and TOETVA

\begin{tabular}{|c|c|c|c|}
\hline Variables & $\mathrm{BABA}(\mathrm{N}=32)$ & TOETVA $(\mathrm{N}=9)$ & $p$ value \\
\hline \multicolumn{4}{|l|}{ Surgical extent } \\
\hline Lobectomy & 3 & 0 & $<0.001$ \\
\hline Total thyroidectomy & 29 & 9 & \\
\hline Central node dissection & 0 & 9 & \\
\hline Tumor size (cm, mean \pm sd) & $2.38 \pm 0.38$ & $1.70 \pm 0.31$ & $<0.001$ \\
\hline Operation time (min, mean \pm sd) & $177.66 \pm 21.02$ & $116.66 \pm 5.59$ & $<0.001$ \\
\hline Blood loss (ml, mean \pm sd) & $149.07 \pm 28.10$ & $102.22 \pm 8.33$ & $<0.001$ \\
\hline \multicolumn{4}{|l|}{ Visual pain score (mean \pm sd) } \\
\hline Postoperative day 1 & $3.59 \pm 0.50$ & $3.44 \pm 0.53$ & 0.462 \\
\hline Postoperative day 2 & $2.59 \pm 0.50$ & $2.44 \pm 0.53$ & 0.462 \\
\hline Hospital stay days after surgery (mean \pm sd) & $3.09 \pm 0.30$ & $2.00 \pm 0.00$ & $<0.001$ \\
\hline \multicolumn{4}{|l|}{ Surgical complications } \\
\hline Vocal cord palsy, transient & 2 & 1 & NA \\
\hline Vocal cord palsy, permanent & 0 & 0 & \\
\hline Hypocalcemia & 5 & 1 & \\
\hline Mental nerve injury & 0 & 0 & \\
\hline Surgical site infection & 0 & 0 & \\
\hline Other complications & 0 & 0 & \\
\hline
\end{tabular}


with papillary thyroid carcinoma who underwent TOETVA. The mean number of lymph nodes was $4.78 \pm 2.82$ (range, 1 10), and the mean number of metastatic lymph nodes was $1.33 \pm 0.87$ (range, 0 3). All patients received radioactive iodine (RAI) therapy, at an initial dose of $120 \mathrm{mCi}$. Radioactive iodine (RAI) is a radiation therapy involving the administration of radioactive iodine to destroy or ablate residual healthy thyroid tissue remaining after thyroidectomy. The mean TSH level before RAI was $73.22 \pm 8.56 \mu \mathrm{IU} / \mathrm{ml}$ (range, $60.0 \sim 82.5 \mu \mathrm{IU} / \mathrm{ml}$ ). The mean TSH stimulated serum thyroglobulin level (sTg) was $0.87 \pm 0.07 \mathrm{ng} / \mathrm{ml}$ (range, 0.76 0.95 ng/ml), with all patients having stimulated serum thyroglobulin below $1.0 \mathrm{ng} / \mathrm{ml}$.

\section{DISCUSSION}

The incidence of thyroid cancer has gradually increased worldwide. ${ }^{2}$ One of the main reasons for increased thyroid cancer in Eastern Europe is exposure to radiation, due to geographic proximity to the Chernobyl nuclear accident area. ${ }^{16,17}$ Georgia and other regions in the Caucasus are also closely located to high radiation areas, resulting in an increased incidence of thyroid cancer over time, from 30 patients in 2007 to 890 in 2016.

Thyroid cancer mostly occurs in younger aged women, leading to the development of surgical approaches that do not leave scars on the visible anterior neck. ${ }^{5,6,12,18}$ Despite the high incidence of thyroid cancer in Eastern Europe, these methods have not yet been widely introduced in these countries, especially in the Caucasus. Our center, located in Tbilisi, the capital of Georgia, was the first in the Caucasus to introduce remote access thyroid surgery, introducing BABA endoscopic thyroid surgery in 2015. Despite the advantages of BABA endoscopic surgery, ${ }^{19}$ this method requires a wide subcutaneous flap around the anterior chest, increasing the effort required to make the flap. This results in BABA requiring a longer operation time than TOETVA, as illustrated in the present study. Furthermore, the use of endoscopic instruments makes the approach to level 6 central lymph nodes very difficult, due to the caudal-cephalic view of the camera and the inferior-to-superior direction of the endoscopic instruments. Proper central node dissection is important in patients with papillary thyroid carcinoma to improve oncologic outcomes, such as staging, and to prevent recurrence. ${ }^{20,21}$ The BABA approach has therefore been largely performed in a da-Vinci robotic assisted manner. Due to these limitations, only patients with benign nodules in this study underwent BABA endoscopic thyroid surgery.

TOETVA was first reported to be successful in 2015, with most of the patients having benign nodules. ${ }^{112}$ TOETVA for thyroid cancer was first performed in 2016, ${ }^{10,13-15}$ with oncologic outcomes similar to those of conventional open surgery. ${ }^{10,22,23}$ For example, the numbers of harvested lymph nodes and stimulated thyroglobulin levels before the first RAI did not differ significantly, indicating that TOETVA was oncologically safe for thyroid cancer surgery. ${ }^{10}$ Our study showed that the mean number of lymph nodes was $4.78 \pm 2.82$ (range, $1 \sim 10$ ), and the mean stimulated $\mathrm{Tg}$ level was $0.87 \pm 0.07 \mathrm{ng} / \mathrm{ml}$ (range, $0.76 \sim 0.95 \mathrm{ng} / \mathrm{ml}$ ), similar to previous results, which showed that the mean number of harvested central lymph nodes in patients who underwent robotic thyroid surgery was $4.5 \pm 2.6$ to $4.7 \pm 3.2$, and that the mean concentration of stimulated $\mathrm{Tg}$ was $0.8 \pm 1.9$ to $1.2 \pm 3.4 \mathrm{ng} / \mathrm{ml}^{24}$

We found that tumor size was significantly larger in the BABA than in the TOETVA $(2.48 \pm 0.38 \mathrm{~cm}$ versus $1.70 \pm 0.31 \mathrm{~cm})$, although both groups showed similar surgical outcomes, including postoperative pain scores, vocal cord palsy, and hypocalcemia. Operation time, however, was a mean 60 min shorter and blood loss a mean $45 \mathrm{ml}$ lower in the TOETVA than in the BABA group, perhaps because TOETVA requires a smaller subcutaneous flap than BABA. In addition, the midline cephalo-caudal approach of TOETVA allows both thyroid glands to be easily seen using the same camera trocar. ${ }^{25}$ Cervical lymph node dissection around levels 6 and 7 was also easier with TOETVA than with the BABA endoscopic view. These results suggest that TOETVA is safe for thyroid cancer patients, with excellent cosmetic outcomes.

To our knowledge, this study is the first to show that these two surgical methods, BABA and TOETVA, are safe and effective methods of scar-less thyroid surgery in an Eastern European country. We think that TOETVA is suitable for selective thyroid cancer surgery requiring central node dissection. However, the major limitation of this study was its inclusion of relatively few patients. In the future, we will prospectively enroll and analyze larger numbers of patients. In addition, to assess the effect of surgical method on survival and recurrence, we will extend the follow-up duration, rather than measure stimulated Tg concentration. Another limitation was the failure to measure objectively hypocalcemia. Our center does not perform routine blood tests for calcium or parathyroid hormone (PTH). We evaluate hypocalcemia by observing patients' clinical symptoms of hypocalcemia. We intend to perform a blood laboratory test for hypocalcemia in future research. The final limitation is that we compared the performances of two different surgical methods for patients with different pathologic thyroid diseases, namely BABA for thyroid nodule(s) and TOETVA for papillary thyroid carcinoma. The reason we made this type of comparison was because the main focus of our study was to judge the performance of a new surgical method at our institution. In the future, we intend to increase the number of cases and compare the performances of BABA and TOETVA for the surgery of one disease entity.

In summary, the present study shows that the Aversi Clinic in Georgia was the first to perform oncoplastic thyroid surgery using the BABA and TOETVA methods without harmful complications. BABA was suitable for large sized benign nodules, and 
TOETVA was suitable for complete removal of thyroid cancers coupled with lymph node dissection.

\section{ORCID}

Jae Cheol Jung, https://orcid.org/0000-0003-0503-1773 Giorgi Chantladze, https://orcid.org/0000-0002-4816-5782 Vladimer Kharebadze, https://orcid.org/0000-0003-4083-9487 Jong-Hyuk Ahn, https://orcid.org/0000-0003-0187-9777 Jae Hwan Kim, https://orcid.org/0000-0003-4286-5080 Jin Wook Yi, https://orcid.org/0000-0002-9296-8443 Edisher Sikharulidze, https://orcid.org/0000-0001-9243-3927

\section{AUTHORS' CONTRIBUTIONS}

Conceptualization: Jin Wook Yi and Edisher Sikharulidze. Formal analysis: Jin Wook Yi, Edisher Sikharulidze, JongHyuk Ahn, Jae Hwan Kim, Giorgi Chantladze, and Vladimer Kharebadze. Methodology: Jin Wook Yi. Writing-original draft: Jae Cheol Jung and Jin Wook Yi. Writing-review and editing: Jae Cheol Jung and Jin Wook Yi.

\section{CONFLICT OF INTEREST}

None.

\section{FUNDING}

This work was supported by the Research Grant from Inha University Hospital.

\section{ACKNOWLEDGMENTS}

None.

\section{REFERENCES}

1) Cabanillas ME, McFadden DG, Durante C. Thyroid cancer. Lancet 2016;388:2783-2795.

2) Bray F, Ferlay J, Soerjomataram I, Siegel RL, Torre LA, Jemal A. Global cancer statistics 2018: GLOBOCAN estimates of incidence and mortality worldwide for 36 cancers in 185 countries. CA Cancer J Clin 2018;68:394-424.

3) Lim H, Devesa SS, Sosa JA, Check D, Kitahara CM. Trends in Thyroid Cancer Incidence and Mortality in the United States, 1974-2013. JAMA 2017;317:1338-1348.

4) La Vecchia C, Malvezzi M, Bosetti C, et al. Thyroid cancer mortality and incidence: a global overview. Int J Cancer 2015;136:2187-2195.

5) Arora A, Swords C, Garas G, et al. The perception of scar cosmesis following thyroid and parathyroid surgery: A prospective cohort study. Int J Surg 2016;25:38-43.

6) Lee J, Kwon IS, Bae EH, Chung WY. Comparative analysis of oncological outcomes and quality of life after robotic versus conventional open thyroidectomy with modified radical neck dissection in patients with papillary thyroid carcinoma and lateral neck node metastases. J Clin Endocrinol Metab 2013;98:2701-2708.

7) Tae K, Ji YB, Song CM, Ryu J. Robotic and Endoscopic Thyroid Surgery: Evolution and Advances. Clin Exp Otorhinolaryngol 2019;12:111.

8) Choe JH, Kim SW, Chung KW, et al. Endoscopic thyroidectomy using a new bilateral axillo-breast approach. World J Surg 2007;31:601606.

9) Choi JY, Lee KE, Chung KW, et al. Endoscopic thyroidectomy via bilateral axillo-breast approach (BABA): review of 512 cases in a single institute. Surg Endosc 2012;26:948-955.

10) Ahn JH, Yi JW. Transoral endoscopic thyroidectomy for thyroid carcinoma: outcomes and surgical completeness in 150 single-surgeon cases. Surg Endosc 2020;34:861-867.

11) Anuwong A, Ketwong K, Jitpratoom P, Sasanakietkul T, Duh QY. Safety and Outcomes of the Transoral Endoscopic Thyroidectomy Vestibular Approach. JAMA Surg 2018;153:21-27.

12) Anuwong A. Transoral Endoscopic Thyroidectomy Vestibular Approach: A Series of the First 60 Human Cases. World J Surg 2016;40: 491-497.

13) Yi JW, Yoon SG, Kim HS, et al. Transoral endoscopic surgery for papillary thyroid carcinoma: initial experiences of a single surgeon in South Korea. Ann Surg Treat Res 2018;95:73-79.

14) Park JO, Sun DI. Transoral endoscopic thyroidectomy: our initial experience using a new endoscopic technique. Surg Endosc 2017;31: 5436-5443.

15) Chai YJ, Chung JK, Anuwong A, et al. Transoral endoscopic thyroidectomy for papillary thyroid microcarcinoma: initial experience of a single surgeon. Ann Surg Treat Res 2017;93:70-75.

16) Iglesias ML, Schmidt A, Ghuzlan AA, et al. Radiation exposure and thyroid cancer: a review. Arch Endocrinol Metab 2017;61:180-187.

17) Bazyka DA, Prysyazhnyuk AY, Fuzik MM, Fedorenko ZP. Thyroid Cancer and the Chornobyl Accident in Ukraine: Experience With the Implementation of a Follow-Up Programme. Radiat Prot Dosimetry 2016;171:32-40.

18) Lee KE, Choi JY, Youn YK. Bilateral axillo-breast approach robotic thyroidectomy. Surg Laparosc Endosc Percutan Tech 2011;21:230236.

19) Kim SJ, Lee KE, Choe JH, et al. Endoscopic completion thyroidectomy by the bilateral axillo-breast approach. Surg Laparosc Endosc Percutan Tech 2010;20:312-316.

20) Hughes DT, Doherty GM. Central neck dissection for papillary thyroid cancer. Cancer Control 2011;18:83-88.

21) Gambardella $C$, Tartaglia E, Nunziata A, et al. Clinical significance of prophylactic central compartment neck dissection in the treatment of clinically node-negative papillary thyroid cancer patients. World J 
Surg Oncol 2016;14:247.

22) Paek SH, Lee HA, Kwon H, Kang KH, Park SJ. Comparison of robotassisted modified radical neck dissection using a bilateral axillary breast approach with a conventional open procedure after propensity score matching. Surg Endosc 2020;34:622-627.

23) Chai YJ, Suh H, Woo JW, et al. Surgical safety and oncological completeness of robotic thyroidectomy for thyroid carcinoma larger than 2 cm. Surg Endosc 2017;31:1235-1240.
24) Lang BH, Wong CK, Tsang JS, Wong KP. A systematic review and meta-analysis comparing outcomes between robotic-assisted thyroidectomy and non-robotic endoscopic thyroidectomy. J Surg Res 2014; 191:389-398.

25) Razavi CR, Khadem MGA, Fondong A, et al. Early outcomes in transoral vestibular thyroidectomy: Robotic versus endoscopic techniques. Head Neck 2018;40:2246-2253. 